\title{
Dynamic positioning system for a ship on harbour manoeuvringwith different observers. Experimental results
}

\author{
Mirosław Tomera, Ph. D. \\ Gdynia Maritime University
}

\begin{abstract}
In cases when the navigational space of the manoeuvre performed by the ship is severely limited, the procedures making use of the rudder blade, propeller screw, and thrusters are very complicated. Such situations take place when the ship manoeuvres inside the harbour area and in those cases the structure of the control system is very complex. The article describes the algorithm of multivariable control of ship motion over the water surface, which makes use of the state vector consisting of 6 variables. Three of them, which are the position coordinates $(x, y)$ measured by the DGPS system and the ship heading $\psi$ measured by gyro-compass, were obtained experimentally. The three remaining variables, which are the velocities in surge $u$, sway $v$, and yaw r directions, were estimated by Kalman filter, KalmanBucy filter and extended Kalman filter, respectively.

The control algorithms making use of these observers were examined using the training ship „Blue Lady” which was navigated on the lake Silm in Ilawa/Kamionka in the Ship Handling Research and Training Centre owned by the Foundation for Safety of Navigation and Environment Protection. The experimental results obtained using control systems with three observers were finally compared between each other.
\end{abstract}

Keywords: Dynamic positioning system, Manoeuvring control, Observers, Real-time experiments.

\section{INTRODUCTION}

Ship manoeuvring in the harbour area is one of most complicated and dangerous types of ship motion control. For this purpose all available actuators are used, including the rudder blade, propeller screw and thrusters. Due to low speed, nonlinear ship dynamics, wide ranges of manoeuvring movements, and complicated harbour environment, the safety of manoeuvring inside the harbour area is of extreme importance, especially in case of large ships. Therefore from the point of view of economy and safety an important issue is designing robust and efficient ship control systems for harbour manoeuvring.

Ship manoeuvring includes selection of the required passing trajectory, complemented by the requirements concerning the expected speed of ship motion along this trajectory. During ship manoeuvring, ship movements in the horizontal plane in surge, sway and yaw directions are to be taken into account. Since all sensors and actuators are used in ship manoeuvring inside the harbour, the controller performing this operation is to be a control system with a number of inputs and outputs. In the automatic control theory such systems bear the name of multivariable control systems. Due to large ship inertia and low speeds near the pier, the environmental disturbances such as wind and water currents affect remarkably the safety of the manoeuvring operations.

The manoeuvring control makes use of techniques developed in dynamic ship positioning systems (DP). The tasks of the DP systems include keeping the ship position constant with the aid of the actuators only, and/or with the aid of mooring lines, and slow tracking of the reference velocity $[1,2]$.

Until the late 1970s, attempts to develop the control systems for sea going vessels were focused on designing various autopilots. The autopilot is a controller which keeps the ship course constant using the rudder blade for ship steering along the assumed direction. In this system the course was measured by a gyro-compass [3]. In the 1980s, commercial autopilot versions appeared on the market which were based on classical course controllers $([4,5,6]$.

With the introduction of precise devices for measuring ship position coordinates in the 1980s, the systems which controlled the ship motion along an assumed trajectory, so-called track-keeping control systems, started to be examined. The track-keeping system could be obtained 
from a conventional ship course control system by simple use of the information coming from the positioning system [7]. A number of complicated controllers were designed to improve the operation of such autopilots, including the adaptive control [8, 9], self-tuning [10], LQG $[11,12], \mathrm{H}_{\infty}[13]$ and those making use of fuzzy logic $[14,15]$ and artificial neural networks [16].

In the 1980s, along with the track-keeping systems as automatic systems focusing on manoeuvres performed inside the harbour and automatic mooring started to be analysed. Solving this problem required a mathematical model of a ship which would model the manoeuvring movements inside the harbour, complemented by a relevant control method. The discussion on an accurate mathematical model of a ship which could be used for manoeuvring control can be found in $[17,18,19,20,21,22]$.

In order to determine correct control, a number of methods were adapted which had been developed in the field of nonlinear and intelligent control. Shouji et al. [23] have formulated a mooring problem as nonlinear and limited by two point values, and used the optimal control techniques for designing the controller. Then the problem was solved in various manoeuvring situations using an iterative coupled gradient method $[24,25]$. However these solutions could not be applied in online ship control systems due to excessively high calculation effort needed to obtain the optimal solution [26]. Sarioz and Narli performed simulation investigations to analyse the use of the manoeuvring control for controlling the motion of large tankers sailing through the Bosphorus Strait connecting the Marmara Sea with the Black Sea, the area in which numerous dangerous accidents have been recorded [27]. The manoeuvring task which ended with ship mooring in the harbour was also solved by developing multivariable neural networks and using them in a ship motion controller $[28,29]$. Skjetne et al. have proposed an adaptive control method, which they examined by controlling the motion of the physical model of a ship bearing the name of Cybership II on shallow water in a laboratory shallowwater tank in Trondheim [30]. Gierusz et al. have developed a ship manoeuvring system which consisted of two different controllers switched on and off depending on the performed tasks [31]. Morawski and Nguyen Cong have developed a controller for ship manoeuvring inside the harbour area using fuzzy logic $[32,33]$. Lee et al. have compared the quality of control of two controllers: the PID controller and the fuzzy controller during bringing the ship to harbour [34]. Bui et al. have proposed the use of four tug boats for ship manoeuvring in harbour, and the method of control of their movements [35].

The article presents the results of experimental investigations of a multivariable ship steering. The nonmeasured velocities as surge $u$, sway $v$ and yaw $r$, were estimated using observer. Studies were conducted with three different observers: the discrete-time Kalman filter [36], the continuous-time Kalman-Bucy filter [37] and the extended Kalman filter [38].

\section{THE MULTIVARIABLE SHIP MOTION CONTROL SYSTEM}

The guidance system is used for planning the passing trajectory from the initial ship position to the target position. In the DP system the guidance system delivers a smooth trajectory with the position coordinates and the course leading to the next position.

When applied in low velocities, the controller calculates three assumed values, which are the longitudinal force, the lateral force and the rotating moment.

The propeller allocation processes the assumed forces and moment obtained from the controller to the required propeller settings, such as the rotational speed of the screw propeller, the blade setting angle, the rudder angle and the azimuth pitch propeller angle.

The main task of the observer is to deliver the low-frequency estimates of the ship's surge $u$, sway $v$ and yaw $r$ velocities.

\section{Guidance system}

Guidance system was designed for tracking the set trajectory and consists in moving the ship along the reference trajectory. Figure 2 shows schematically sample ship motion from the initial position $\mathrm{P}$ to the target position $\mathrm{K}$. To define this motion three coordinate systems were introduced. The first coordinate system is the Cartesian system $x^{n} y^{n}$ fixed to the map of the water region in the tangential plane to the Earth surface in the area in which the manoeuvre is performed. In this system the $\mathrm{x}^{\mathrm{n}}$ axis is directed north and the $\mathrm{y}^{\mathrm{n}}$ axis is directed east. This reference system refers to the navigation over the Earth surface and, for simplicity, bears the name of the $\mathrm{n}$-frame. The second coordinate system $\mathrm{x}^{\mathrm{b}} \mathrm{y}^{\mathrm{b}}$ is movable and fixed to the moving ship. Here the $\mathrm{x}^{\mathrm{b}}$ axis is directed along the longitudinal axis of the ship, from stern to bow, while the $\mathrm{y}^{\mathrm{b}}$ axis is the lateral axis directed toward the starboard side. The ship position (x,y) and heading $\psi$ are determined with respect to the stationary coordinate system ( $n$-frame) and are collected in the position vector $\eta=[x, y, \psi]^{\mathrm{T}}$, while the linear speeds $(\mathrm{u}, \mathrm{v})$ and the angular speed $\mathrm{r}$ are determined in the movable coordinate system $x^{b} y^{b}$ and collected in the velocity vector $\mathrm{v}=[\mathrm{u}, \mathrm{v}, \mathrm{r}]^{\mathrm{T}}$.

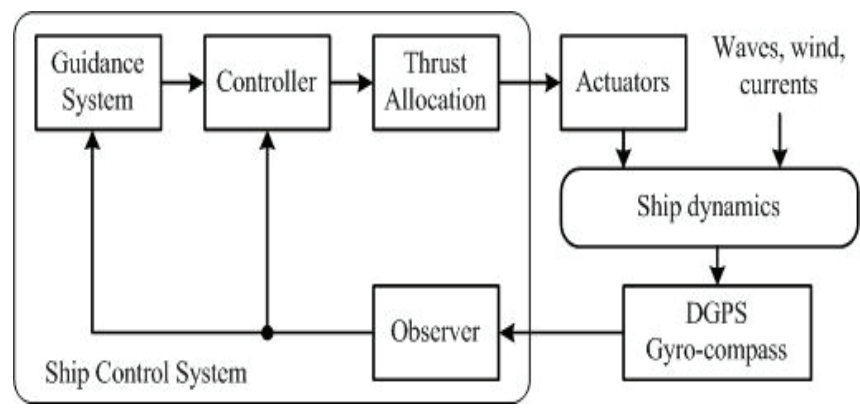

Fig. 1. Block diagram of ship control system and its major components 


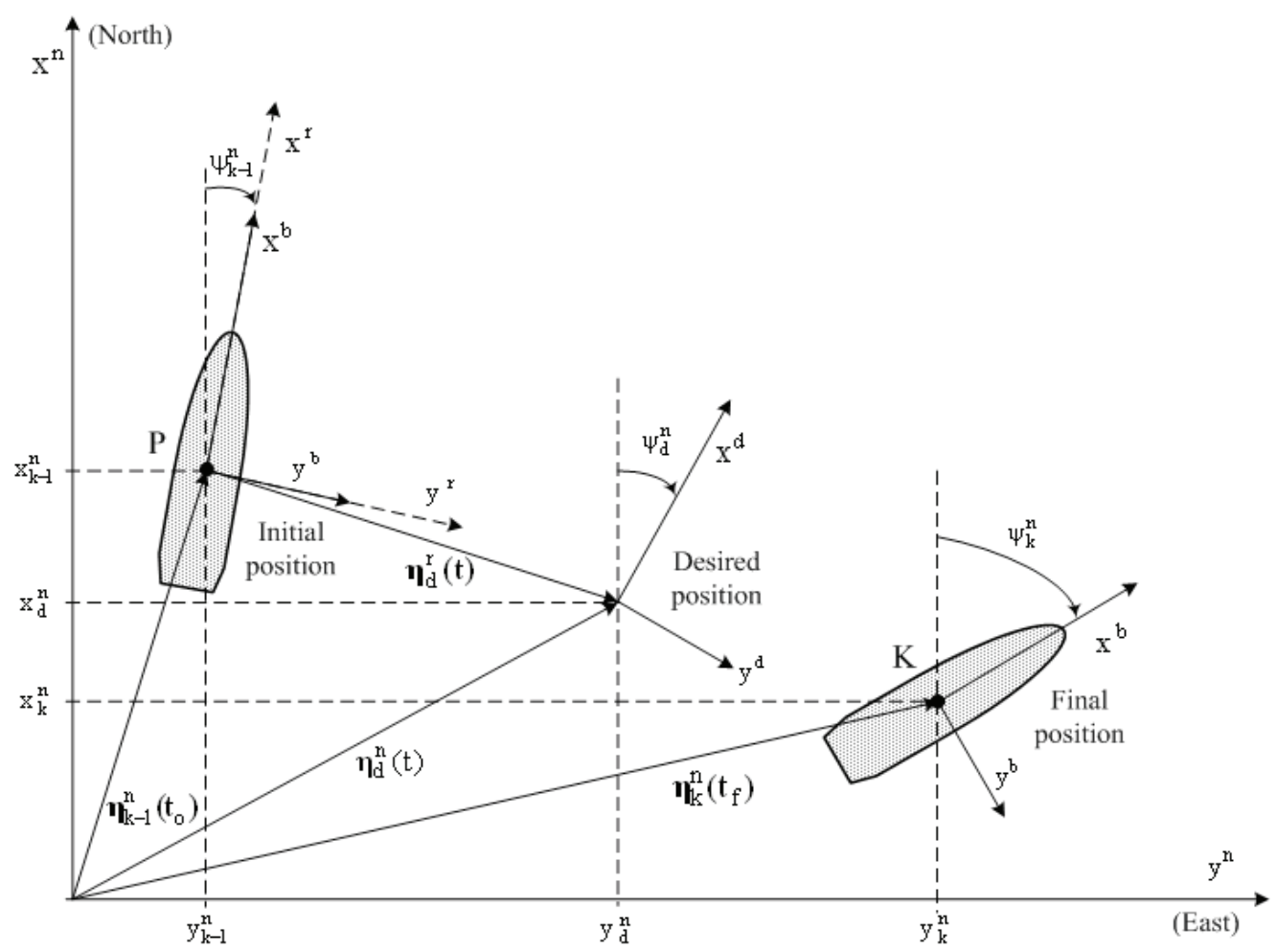

Fig. 2. Definition of the introduced reference systems and positions of the vehicle changing location [39]

The origin of the movable coordinate system is usually placed in the ship's centre of gravity. The motion of the ship changing the position is also described using the third coordinate system $\mathrm{x}^{\mathrm{r}} \mathrm{y}^{\mathrm{r}}$ bearing the name of the reference coordinate system, the $r$-frame. This system is used for describing the ship motion from the initial point $\mathrm{P}$ to the final point $\mathrm{K}$. This coordinate system has the same properties as the $\mathrm{n}$-frame, with the only exception that the direction of the sense of the $\mathrm{x}^{\mathrm{r}}$ axis changes and the coordinates of the origin of this system are each time shifted to the initial point $P$ of the current trajectory segment.

$$
\eta_{K}^{r}=\left(\eta_{k}^{n}-\eta_{p}^{n}\right) \cdot R\left(\psi_{k-1}^{n}\right)
$$

where $\mathbf{R}(\phi)$ is the rotation matrix defined as

$$
\mathbf{R}\left(\psi_{\mathrm{k}-1}^{\mathrm{n}}\right)=\left[\begin{array}{ccc}
\cos \psi_{\mathrm{k}-1}^{\mathrm{n}} & \sin \psi_{\mathrm{k}-1}^{\mathrm{n}} & 0 \\
-\sin \psi_{\mathrm{k}-1}^{\mathrm{n}} & \cos \psi_{\mathrm{k}-1}^{\mathrm{n}} & 0 \\
0 & 0 & 1
\end{array}\right]
$$

The coordinates of position $\eta_{d}^{r}(t)$, velocity $\dot{\eta}_{d}^{r}(t)$ and acceleration $\ddot{\eta}_{d}^{r}(t)$ of the virtual ship moving from the initial point $\mathrm{P}$ to the final point $\mathrm{K}$ are calculated in the reference system shown in Fig. 3.

\section{Mathematical model of ship dynamics}

The object of control for which the presented control algorithm was prepared is the training ship bearing the name of "Blue Lady", which sails on the lake Silm near Ilawa in the Ship Handling Research and Training Centre owned by the Foundation for Safety of Navigation and Environment Protection [40]. This ship is used for training captains to perform complicated and difficult manoeuvres with large ship in various navigational situations and on various water regions (harbours, narrow navigational channels, shallows, rivers, etc.). "Blue Lady" is an isomorphic model of a VLCC (Very Large Crude Carrier) tanker, the displacement of which is $176000 \mathrm{DWT}$. The model is made of epoxide laminate in scale 1:24 (Fig. 4). The main particulars of "Blue Lady" are collected in Table 1.

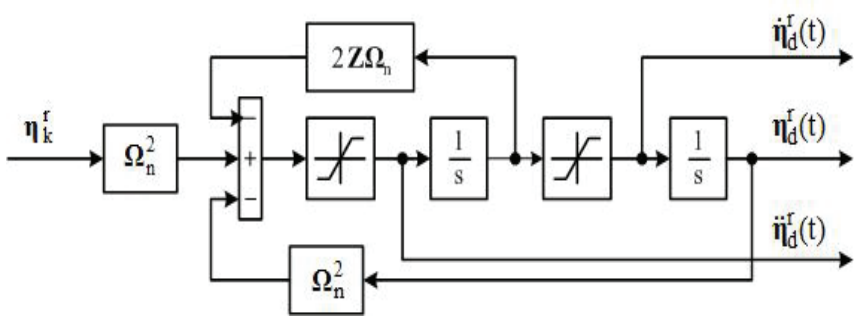

Fig. 3. Reference system command generator for DP contro ller [39] 


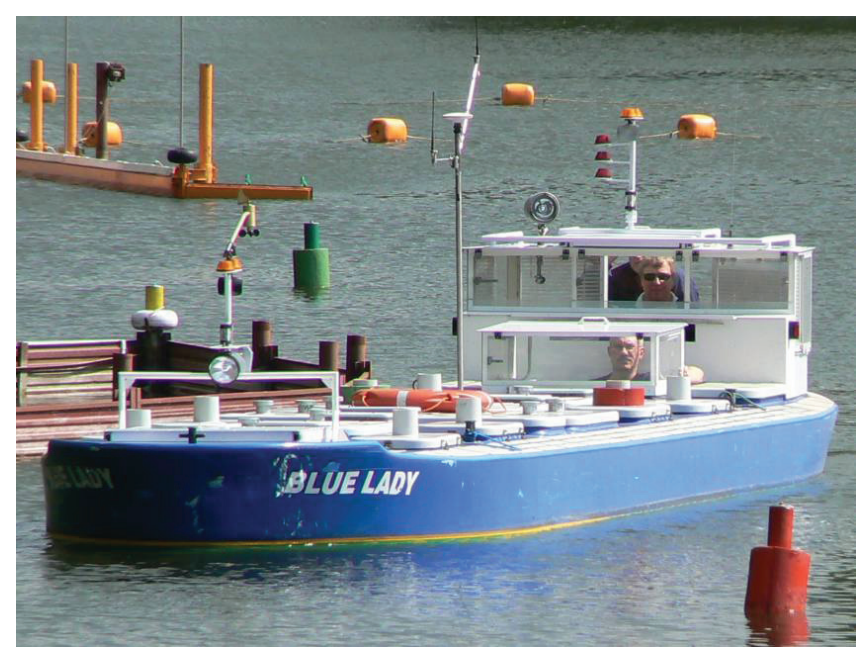

Fig. 4. The view of the ship "Blue Lady" [40]

The manoeuvring system of "Blue Lady" consists of one rudder blade, one propeller screw, two tunnel thrusters (one at bow and one at stern), and two rotating thrusters (one at bow and one at stern). The locations of all installed propellers are shown in Fig. 5.

The control of all these propellers makes use of a set of eight commands:

- rudder blade angle deflection $-\delta_{c}(\mathrm{deg})$,

- revolutions of the main propeller $-\mathrm{n}_{1 c}(\mathrm{rpm})$,

- relative revolutions of a propeller of the bow (stern) tunnel thruster $-p_{2 c}\left(p_{3 c}\right)$,

- turn angle of the movable bow (stern) thruster $-\alpha_{b c}$, $\left(\alpha_{\mathrm{sc}}\right)(\mathrm{deg})$,

- relative revolutions of a propeller of the movable bow (stern) thruster $-\mathrm{p}_{\mathrm{bpc}}\left(\mathrm{p}_{\mathrm{spc}}\right)(-)$.

In the developed multivariable control system only three propellers are used, which are the main propeller, and the two tunnel thrusters. The complex mathematical model of "Blue Lady" dynamics, including the modelled actuators,

Tab. 1. Main particulars of the ship "Blue Lady"

\begin{tabular}{|c|c|}
\hline Overall length $\left(\mathrm{L}_{\mathrm{OA}}\right)[\mathrm{m}]$ & 13.78 \\
\hline Length between perpendiculars [m] & 13.50 \\
\hline Breadth [m] & 2.38 \\
\hline Mean draught (full load) [m] & 0.86 \\
\hline Displacement (full load) [m³] & 22.83 \\
\hline Nominal $x$ coordinate of CG $\left(x_{G}\right)[m]$ & 0.00 \\
\hline Maximal speed [knots] & 3.10 \\
\hline
\end{tabular}

which well reflects real behaviour of the training ship, was worked out by Gierusz [19].

The dynamic positioning system is designed for controlling the low-speed ship motion. The proposed multivariable controller applied in the DP system will be determined based on the mathematical model of the ship at low speeds, described by the following formulas [3].

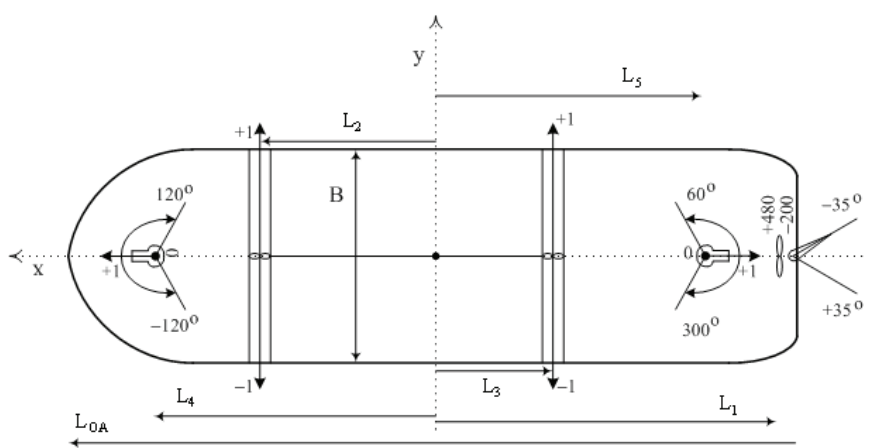

Fig. 5. Thrusters location on "Blue Lady" [39]

$$
\begin{gathered}
\dot{\eta}=R(\psi) v \\
M \dot{v}+D_{L} v=\tau
\end{gathered}
$$

where $\mathbf{R}(\psi)$ is the rotation matrix:

$$
\mathbf{R}(\psi)=\left[\begin{array}{ccc}
\cos \psi & -\sin \psi & 0 \\
\sin \psi & \cos \psi & 0 \\
0 & 0 & 1
\end{array}\right]
$$

The matrix $\mathbf{M}$ includes the inertia parameters of a rigid body: its dimensions, weight, mass distribution, volume, etc. and the added mass coefficients.

$$
M=\left[\begin{array}{ccc}
m-X_{\dot{u}} & 0 & 0 \\
0 & m-Y_{\dot{v}} & m x_{G}-Y_{\dot{r}} \\
0 & m x_{G}-N_{\dot{v}} & I_{z}-N_{\dot{r}}
\end{array}\right]
$$

The linear damping matrix $\quad \mathrm{D}_{\mathrm{L}}$ refers to hydrodynamic damping forces and is calculated for a given low and constant longitudinal speed $v=v_{0} \approx\left[u_{0}, 0,0\right]^{\mathrm{T}}[41]$.

$$
\mathrm{D}_{\mathrm{L}}=\left[\begin{array}{ccc}
-\mathrm{X}_{\mathrm{u}} & 0 & 0 \\
0 & -\mathrm{Y}_{\mathrm{v}} & -\mathrm{Y}_{\mathrm{r}} \\
0 & -\mathrm{N}_{\mathrm{v}} & -\mathrm{N}_{\mathrm{r}}
\end{array}\right]
$$

It is assumed that the position vector $\eta$ and the speed vector $v$ are measured. The parameters calculated for the "Blue Lady" model ship at the speed $\mathrm{u}_{0}=0.1(\mathrm{~m} / \mathrm{s})$, are collected in Table 2. 
Tab. 2. Parameters of the simplified mathematical model of "Blue Lady"

\begin{tabular}{|c|c|r|r|c|c|}
\hline No & Variable & Value & No & Variable & Value \\
\hline 1. & $\mathrm{X}_{\dot{\mathrm{u}}}$ & -730.50 & 6. & $\mathrm{X}_{\mathrm{u}}$ & -21.10 \\
\hline 2. & $\mathrm{Y}_{\dot{\mathrm{v}}}$ & -1896.20 & 7. & $\mathrm{Y}_{\mathrm{v}}$ & -259.80 \\
\hline 3. & $\mathrm{Y}_{\dot{\mathrm{r}}}$ & -18351.90 & 8. & $\mathrm{Y}_{\mathrm{r}}$ & -855.40 \\
\hline 4. & $\mathrm{~N}_{\dot{\mathrm{v}}}$ & 0.00 & 9. & $\mathrm{~N}_{\mathrm{v}}$ & -855.40 \\
\hline 5. & $\mathrm{~N}_{\dot{\mathrm{r}}}$ & 0.00 & 10. & $\mathrm{~N}_{\mathrm{r}}$ & -6130.50 \\
\hline
\end{tabular}

The following mathematical models of propellers used in the control system were analysed for low speed. The thrust force for the main propeller is

$$
\mathrm{F}_{1}=\mathrm{k}_{1}\left|\mathrm{n}_{1}\right| \mathrm{n}_{1}
$$

where $\mathrm{k}_{1}=1.9589$ and $\mathrm{n}_{1}$ is the revolution of the screw propeller. The thrust forces: $\mathrm{F}_{2}$ for the bow tunnel thruster and $\mathrm{F}_{3}$ for the stern tunnel thruster are given by the formulas

$$
\mathrm{F}_{\mathrm{i}}=\mathrm{k}_{\mathrm{i}} \mathrm{p}_{\mathrm{i}}, \quad \mathrm{i} \in\{2,3\}
$$

where $\mathrm{k}_{2}=\mathrm{k}_{3}=44145$, while $p_{2}$ and $p_{3}$ are the relative revolutions of propellers.

The forces generated by the thrusters are the following

$$
\mathbf{u}_{\mathrm{c}}=\left[\begin{array}{lll}
\mathrm{F}_{1} & \mathrm{~F}_{2} & \mathrm{~F}_{3}
\end{array}\right]^{\mathrm{T}}
$$

The vector of forces acting on the ship in relation with these thrusters are

$$
\begin{gathered}
\tau_{c}=T u_{c} \\
{\left[\begin{array}{c}
\tau_{X} \\
\tau_{Y} \\
\tau_{N}
\end{array}\right]=\left[\begin{array}{ccc}
1 & 0 & 0 \\
0 & 1 & 1 \\
0 & L_{2} & -L_{3}
\end{array}\right] \cdot\left[\begin{array}{c}
F_{1}\left(n_{1}\right) \\
F_{2}\left(p_{2}\right) \\
F_{3}\left(p_{3}\right)
\end{array}\right]}
\end{gathered}
$$

where $\mathrm{L}_{2}=3.24[\mathrm{~m}], \mathrm{L}_{3}=2.376[\mathrm{~m}]$. The matrix $\mathbf{T}$ is the propeller configuration matrix.

\section{Multivariable controller}

The control task consists in keeping track of the required smooth trajectory $\left(\eta_{d}^{r}(t), \dot{\eta}_{d}^{r}(t), \ddot{\eta}_{d}^{r}(t)\right)$ delivered by the ship navigation system. In the control systems the deviations from the set values will be calculated, out of which the position deviation $\eta_{\mathrm{e}}$ will be calculated in the stationary $\mathrm{r}$-frame, while the speed and acceleration deviations will be determined in the movable b-frame fixed to the moving ship.

$$
\eta_{e}^{r}=\eta^{r}-\eta_{d}^{r}
$$

$$
\begin{gathered}
\dot{\eta}_{e}^{b}=\dot{\eta}^{b}-\dot{\eta}_{d}^{b}=\dot{\eta}-R^{T}\left(\psi_{e}\right) \cdot \dot{\eta}_{d}^{r} \\
\ddot{\eta}_{e}^{b}=\ddot{\eta}^{b}-\ddot{\eta}_{d}^{b}=\ddot{\eta}^{b}-\dot{\psi}_{e} S^{\top} R^{\top}\left(\psi_{e}\right) \cdot \dot{\eta}_{d}^{r}-R^{\top}\left(\psi_{e}\right) \cdot \ddot{\eta}_{d}^{r}
\end{gathered}
$$

where $\psi_{\mathrm{e}}=\psi-\psi_{\mathrm{d}}$, and the rotation matrix $\mathbf{R}\left(\psi_{\mathrm{e}}\right)$ is calculated using formula (5). The matrix $\mathbf{S}$ has the following form:

$$
\mathbf{S}=\left[\begin{array}{rrr}
0 & -1 & 0 \\
1 & 0 & 0 \\
0 & 0 & 0
\end{array}\right]
$$

In the DP control system a controller will be used which will stabilise the dynamics of the deviation, i.e.

$$
\dot{\xi}_{e}^{r}=\eta_{e}^{r}
$$

$$
\ddot{\eta}_{e}^{b}+K_{D} \dot{\eta}_{e}^{b}+K_{p} \eta_{e}^{r}+K_{1} \xi_{e}^{r}=0
$$

After determining the ship acceleration $\ddot{\eta}^{\mathrm{b}}$ from formula (18) we arrive at:

$$
\ddot{\eta}^{b}=\ddot{\eta}_{d}^{b}-K_{D} \dot{\eta}_{e}^{b}-K_{p} \eta_{e}^{r}-K_{1} \xi_{e}^{r}
$$

Based on equation (4), the proposed law of control will be given by the formula

$$
\tau_{c}=M \dot{v}+D_{L} v
$$

The velocity vector derivative $\dot{v}$ in equation (20) is determined via differentiation of the kinetic equation (3) with respect to time, which gives us the searched relation

$$
\dot{v}=R^{-1}(\psi)\left[\ddot{\eta}^{b}-\dot{R}(\psi) v\right]
$$

The derivative of the rotation matrix $\mathbf{R}(\psi)$ is calculated from the formula

$$
\dot{\mathrm{R}}(\psi)=\mathrm{rR}(\psi) \mathrm{S}
$$

where $r=\psi$. After placing the relation (19) to equation (21), and then to the proposed law of control (20), we arrive at the formula describing the algorithm of operation of the multivariable DP controller

$\tau_{c}=M R^{-1}(\psi)\left[\ddot{\eta}_{d}^{b}-K_{D} \dot{\eta}_{e}^{b}-K_{P} \eta_{e}^{r}-K_{1} \xi_{e}^{r}-r R(\psi) S v\right]+D_{L} v$

\section{Allocation of propellers}

The control allocation problem appears when the number 
of actuators is larger than the number of controlled degrees of freedom. The algorithm can be executed in two steps, as shown in Fig. 6.

In the first step, bearing the name of force allocation, the set generalised force $\tau_{c}$ is decomposed into all propellers of interest. The quality of the decision made at this step depends on how good the force allocation algorithm is. The second step consists in finding settings for the actuators which will lead to the generation of the required forces $\mathbf{F}$. This step is called the inverse transformation, as it consists in finding the inverse characteristics of the actuators.

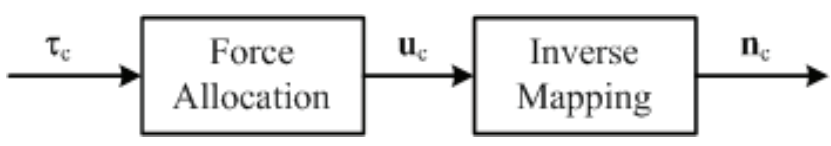

Fig. 6. The thrust allocation problem considered as a two-step process [39]

In the analysed DP system three propellers having the configuration shown in Fig. 2 were used for ship motion control. In this case the force allocation consists in solving the equation

$$
\begin{gathered}
\mathrm{u}=\mathrm{T}^{-1} \tau_{\mathrm{c}} \\
{\left[\begin{array}{l}
\mathrm{F}_{1} \\
\mathrm{~F}_{2} \\
\mathrm{~F}_{3}
\end{array}\right]=\left[\begin{array}{ccc}
1 & 0 & 0 \\
0 & 1 & 1 \\
0 & L_{2} & -L_{3}
\end{array}\right]^{-1}\left[\begin{array}{c}
\tau_{X} \\
\tau_{Y} \\
\tau_{N}
\end{array}\right]}
\end{gathered}
$$

After decomposing the forces into particular propellers, the transformation of formulas (8) and (9) gives the command values for the main propulsion propeller

$$
\mathrm{n}_{1 \mathrm{c}}=\operatorname{sgn}\left(\mathrm{F}_{1}\right) \sqrt{\mathrm{F}_{1} / \mathrm{k}_{1}}
$$

and for the tunnel thrusters

$$
\mathrm{p}_{\mathrm{ic}}=\mathrm{F}_{\mathrm{i}} / \mathrm{k}_{\mathrm{i}}, \quad \mathrm{i} \in\{2,3\}
$$

The command revolution of the main propeller $\left(\mathrm{n}_{1 \mathrm{c}}\right)$ is to be limited to the physically existing range $-200 \ldots+480$ ( $\mathrm{rpm})$, while the desired relative revolution of propellers for the bow $\left(\mathrm{p}_{2 \mathrm{c}}\right)$ and stern $\left(\mathrm{p}_{3 \mathrm{c}}\right)$ tunnel thrusters are to be kept within the range $\pm 1(-)$.

\section{OBSERVERS USED FOR ESTIMATING THE SHIP VELOCITIES}

The problems of filtration and state estimation are of high importance in dynamic positioning systems. In many cases the ship velocity measurements are not available and in those cases the velocity estimates should be determined by the stateobserver based on the noised measurements of ship's position and heading.

The first observer used to estimate the unmeasured velocities of the ship ( $u, v, r)$ in multivariable control system shown in Figure 1, was a nonlinear observer [38]. However, during preliminary simulation studies of designed multivariable control system that uses a nonlinear observer, problems with the stability of the overall control system appeared.

For this reason, the search for new observers to replace the nonlinear observer began. Author reached for observers based on the Kalman filter, using observers such as discrete Kalman filter, continuous Kalman filter and extended Kalman filter to estimate the unmeasured velocities. During the experimental tests carried out on the lake Silm in Ilawa/Kamionka, the control system that uses a nonlinear observer was unstable, while other control systems with observers based on the Kalman filter worked steadily. For this reason, in the following discussion nonlinear observer is omitted.

\section{Discrete-time Kalman filter}

The discrete-time Kalman filter tries to estimate optimally the state vector of the controlled process, which is modelled by the linear, stochastic difference equation having the form [42].

$$
\mathbf{x}_{\mathrm{k}+1}=\mathbf{F}_{\mathrm{k}} \mathbf{x}_{\mathrm{k}}+\mathbf{G}_{\mathrm{k}} \mathbf{w}_{\mathrm{k}}
$$

The observations (measurements) of the process are done at discrete times and are described by the following linear relation

$$
\mathbf{y}_{\mathrm{k}}=\mathbf{H}_{\mathrm{k}} \mathbf{x}_{\mathrm{k}}+\mathbf{v}_{\mathrm{k}}
$$

where $\mathbf{x}_{k}$ is the state vector of the process at time $t_{k}, F_{k}$ is the matrix which refers $\mathbf{x}_{\mathrm{k}}$ to $\mathbf{x}_{\mathrm{k}+1}$ at the absence of the exciting force, $\mathbf{w}_{\mathrm{k}}$ are the random disturbances affecting the process, $\mathbf{G}_{\mathrm{k}}$ is the matrix which scales the amplitude of the process disturbances, $\mathbf{y}_{k}$ is the vector of the values measured at time $t_{k}, H_{k}$ is the matrix linking the measurements with the state vector at time $t_{k}$, and $\mathbf{v}_{k}$ describes the measurement errors. It is assumed that the signals $\mathbf{v}_{\mathrm{k}}$ and $\mathbf{w}_{\mathrm{k}}$ have the mean value equal

\begin{tabular}{|c|c|}
\hline Design matrices & $\mathbf{Q}_{\mathrm{k}}=\mathbf{Q}_{\mathrm{k}}^{\mathrm{T}}>0, \quad \mathbf{R}_{\mathrm{k}}=\mathbf{R}_{\mathrm{k}}^{\mathrm{T}}>0$ \\
\hline Initial conditions & $\overline{\mathbf{x}}(0)=\mathbf{x}_{0}, \overline{\mathbf{P}}(0)=\mathbf{P}_{0}$ \\
\hline Kalman gain matrix & $\mathbf{L}_{\mathrm{k}}=\overline{\mathbf{P}}_{\mathrm{k}} \mathbf{H}_{\mathrm{k}}^{\mathrm{T}}\left[\mathbf{H}_{\mathrm{k}} \overline{\mathbf{P}}_{\mathrm{k}} \mathbf{H}_{\mathrm{k}}^{\mathrm{T}}+\mathbf{R}_{\mathrm{k}}\right]^{-1}$ \\
\hline State estimate update & $\hat{\mathbf{x}}_{\mathrm{k}}=\overline{\mathbf{x}}_{\mathrm{k}}+\mathbf{L}_{\mathrm{k}}\left[\mathbf{y}_{\mathrm{k}}-\mathbf{H}_{\mathrm{k}} \overline{\mathbf{x}}_{\mathrm{k}}\right]$ \\
\hline $\begin{array}{l}\text { Error covariance } \\
\text { update }\end{array}$ & $\hat{\mathbf{P}}_{\mathrm{k}}=\overline{\mathbf{P}}_{\mathrm{k}}-\overline{\mathbf{P}}_{\mathrm{k}} \mathbf{H}_{\mathrm{k}}^{\mathrm{T}}\left[\mathbf{H}_{\mathrm{k}} \overline{\mathbf{P}}_{\mathrm{k}} \mathbf{H}_{\mathrm{k}}^{\mathrm{T}}+\mathbf{R}_{\mathrm{k}}\right]^{-1} \mathbf{H}_{\mathrm{k}} \overline{\mathbf{P}}_{\mathrm{k}}$ \\
\hline $\begin{array}{l}\text { State estimate } \\
\text { propagation }\end{array}$ & $\overline{\mathbf{x}}_{\mathrm{k}+1}=\mathbf{F}_{\mathrm{k}} \hat{\mathbf{x}}_{\mathrm{k}}$ \\
\hline $\begin{array}{l}\text { Error covariance } \\
\text { propagation }\end{array}$ & $\overline{\mathbf{P}}_{\mathrm{k}+1}=\mathbf{F}_{\mathrm{k}} \mathbf{P}_{\mathrm{k}} \mathbf{F}_{\mathrm{k}}^{\mathrm{T}}+\mathbf{G}_{\mathrm{k}} \mathbf{Q}_{\mathrm{k}} \mathbf{G}_{\mathrm{k}}^{\mathrm{T}}$ \\
\hline
\end{tabular}
to zero and that there is no correlation between them [42].

Details concerning the derivation of the algorithm based on which the discrete Kalman filter works, and the way in which the estimation of ship velocity is performed can be

Tab. 3. Discrete-time Kalman filter [36, 43] 
Tab. 4. Continous-time Kalman-Bucy filter [37,43]

$\begin{array}{ll}\text { Design matrices } & \mathbf{Q}(\mathrm{t})=\mathbf{Q}^{\mathrm{T}}(\mathrm{t})>0, \quad \mathbf{R}(\mathrm{t})=\mathbf{R}^{\mathrm{T}}(\mathrm{t})>0, \\ & \mathbf{x}(0)=\mathbf{x}_{0}, \quad \mathbf{P}(0)=\mathbf{P}_{0}, \\ \begin{array}{l}\text { Initial conditions } \\ \begin{array}{l}\text { Kalman gain matrix } \\ \text { propagation }\end{array}\end{array} & \mathbf{L}(\mathrm{t})=\mathbf{P}(\mathrm{t}) \mathbf{H}^{\mathrm{T}}(\mathrm{t}) \mathbf{R}^{-1}(\mathrm{t}) \\ \begin{array}{l}\text { State estimate } \\ \text { propagation }\end{array} & \dot{\hat{\mathbf{x}}}(\mathrm{t})=\mathbf{A}(\mathrm{t}) \hat{\mathbf{x}}(\mathrm{t})+\mathbf{L}(\mathrm{t})[\mathrm{y}(\mathrm{t})-\mathbf{C}(\mathrm{t}) \hat{\mathbf{x}}(\mathrm{t})] \\ & \dot{\mathbf{P}}(\mathrm{t})=\mathbf{A}(\mathrm{t}) \mathbf{P}(\mathrm{t})+\mathbf{P}(\mathrm{t}) \mathbf{A}(\mathrm{t})+\mathbf{G}(\mathrm{t}) \mathbf{Q}(\mathrm{t}) \mathbf{G}(\mathrm{t})- \\ \begin{array}{l}\text { Error covariance } \\ \text { propagation }\end{array} & -\mathbf{P}(\mathrm{t}) \mathbf{C}(\mathrm{t}) \mathbf{R}^{-1}(\mathrm{t}) \mathbf{C}(\mathrm{t}) \mathbf{P}(\mathrm{t}) \\ & \end{array}$

found in [36]. The discrete-time Kalman filter algorithm is given in table 3 .

Recursively determined gains of discrete-time Kalman filter $\mathbf{L}$ according to an algorithm contained in Table 3 are steady-state within the first twelve seconds. To simplify the program code implementing the algorithm of discrete-time Kalman filter in calculations of estimates fixed values of gains obtained by using the function dlqr contained in the Matlab were used. In particular tracks of estimation the following gain values were applied

$$
\mathrm{L}_{\mathrm{x}}=\mathrm{L}_{\mathrm{y}}=\mathrm{L}_{\psi}=\left[\begin{array}{l}
0.07945 \\
0.36868
\end{array}\right]
$$

\section{Continuous-time Kalman-Bucy filter}

The equation describing the continuous Kalman-Bucy filter are obtained from those describing the discrete Kalman filter by decreasing the sampling interval $\Delta t \rightarrow 0$. This continuous process is described by the equation

$$
\begin{gathered}
\dot{x}(t)=A(t) x(t)+G(t) w(t) \\
y(t)=C(t) x(t)+v(t)
\end{gathered}
$$

where $w$ and $v$ are zero-mean Gaussian white noise processes. Details concerning the derivation of the equations describing the continuous Kalman-Bucy filter and the way in which it was used for estimating ship velocities can be found in [37].

In paper were used the steady-state solution for continoustime Kalman filter given by

$$
\mathbf{L}(\mathrm{t})=\mathrm{L}_{\infty}=\mathbf{P}_{\infty} \mathbf{C}^{\mathrm{T}} \mathbf{R}^{-1}
$$

where $\mathbf{P}_{\infty}=\mathbf{P}_{\infty}^{\mathrm{T}}>0$ is the positive definite solution of the algebraic matrix Riccati equation

$$
A P_{\infty}+P_{\infty} A^{\top}+G Q G^{\top}-P_{\infty} C^{\top} R^{-1} C P_{\infty}=0(34)
$$

The steady-state values of gains $\mathbf{L}_{\infty}$ were determined by the function lqr from the library of Matlab. In particular tracks of estimation the following gain values were used

$$
\mathrm{L}_{x \infty}=\mathrm{L}_{y \infty}=\mathrm{L}_{\psi \infty}=\left[\begin{array}{c}
0.1 \\
0.45826
\end{array}\right]
$$

\section{Extended Kalman filter}

A design of the extended Kalman filter for the multivariable system of ship motion control will be based on the nonlinear model having the following form:

$$
\begin{gathered}
\dot{x}(t)=f(x(t))+E w(t) \\
y(t)=H x(t)+v(t)
\end{gathered}
$$

where the matrices $\mathbf{f}(\mathbf{x}(\mathrm{t})), \mathbf{E}$ and $\mathbf{H}$ take the following forms [38]

$$
\begin{gathered}
f(x(t))=\left[\begin{array}{c}
R(\psi(t)) v(t) \\
-M^{-1} D_{L} v(t)+M^{-1} R^{\top}(\eta(t)) \\
-T_{b}^{-1}
\end{array}\right] \\
E=\left[\begin{array}{c}
0_{3 \times 3} \\
0_{3 \times 3} \\
E_{b}
\end{array}\right] \\
H=\left[\begin{array}{lll}
I_{3 \times 3} & 0_{3 \times 3} & 0_{3 \times 3}
\end{array}\right]
\end{gathered}
$$

\begin{tabular}{|c|c|}
\hline Design matrices & $\mathbf{Q}_{\mathrm{k}}=\mathbf{Q}_{\mathrm{k}}^{\mathrm{T}}>0, \quad \mathbf{R}_{\mathrm{k}}=\mathbf{R}_{\mathrm{k}}^{\mathrm{T}}>0$ \\
\hline Initial conditions & $\overline{\mathbf{x}}(0)=\mathbf{x}_{0}, \quad \overline{\mathbf{P}}(0)=\mathbf{P}_{0}$ \\
\hline Kalman gain matrix & $\mathbf{L}_{\mathrm{k}}=\overline{\mathbf{P}}_{\mathrm{k}} \mathbf{H}_{\mathrm{k}}^{\mathrm{T}}\left[\mathbf{H}_{\mathrm{k}} \overline{\mathbf{P}}_{\mathrm{k}} \mathbf{H}_{\mathrm{k}}^{\mathrm{T}}+\mathbf{R}_{\mathrm{k}}\right]^{-1}$ \\
\hline State estimate update & $\hat{\mathbf{x}}_{\mathrm{k}}=\overline{\mathbf{x}}_{\mathrm{k}}+\mathbf{L}_{\mathrm{k}}\left[\mathbf{y}_{\mathrm{k}}-\mathbf{H}_{\mathrm{k}} \overline{\mathbf{x}}_{\mathrm{k}}\right]$ \\
\hline Error covariance update & $\hat{\mathbf{P}}_{\mathrm{k}}=\overline{\mathbf{P}}_{\mathrm{k}}-\overline{\mathbf{P}}_{\mathrm{k}} \mathbf{H}_{\mathrm{k}}^{\mathrm{T}}\left[\mathbf{H}_{\mathrm{k}} \overline{\mathbf{P}}_{\mathrm{k}} \mathbf{H}_{\mathrm{k}}^{\mathrm{T}}+\mathbf{R}_{\mathrm{k}}\right]^{-1} \mathbf{H}_{\mathrm{k}} \overline{\mathbf{P}}_{1}$ \\
\hline $\begin{array}{l}\text { State estimate } \\
\text { propagation }\end{array}$ & $\overline{\mathbf{x}}_{\mathrm{k}+1}=\ddot{\mathbf{O}}\left(\hat{\mathbf{x}}_{\mathrm{k}}\right)$ \\
\hline $\begin{array}{l}\text { Error covariance } \\
\text { propagation }\end{array}$ & $\overline{\mathbf{P}}_{\mathrm{k}+1}=\mathbf{F}_{\mathrm{k}} \hat{\mathbf{P}}_{\mathrm{k}} \mathbf{F}_{\mathrm{k}}^{\mathrm{T}}+\mathbf{G}_{\mathrm{k}} \mathbf{Q}_{\mathrm{k}} \mathbf{G}_{\mathrm{k}}^{\mathrm{T}}$ \\
\hline
\end{tabular}

Here: $\mathbf{x}=\left[\begin{array}{lll}\eta & v & \mathbf{b}\end{array}\right]^{\mathrm{T}}, \quad \mathbf{w}=\mathbf{w}_{\mathrm{b}}$. The matrix $\mathbf{f}(\mathbf{x}(\mathrm{t}))$ is a nonlinear vector field.

The extended Kalman filter is derived in the discrete form. For this purpose the linearized state equation (36) and the output equation (37) are written in the following discrete form

$$
\mathbf{x}_{\mathrm{k}+1}=\mathbf{F}_{\mathrm{k}} \mathbf{x}_{\mathrm{k}}+\mathbf{G}_{\mathrm{k}} \mathbf{w}_{\mathrm{k}}
$$

$$
\mathbf{y}_{\mathrm{k}}=\mathbf{H} \mathbf{x}_{\mathrm{k}}+\mathbf{v}_{\mathrm{k}}
$$

Tab. 5. Discrete-time extended Kalman Filter [38, 43$]$ 
where matrices $\quad \mathbf{F}_{\mathrm{k}}$ and $\mathbf{G}_{\mathrm{k}}$ can be determined using the Euler forward method and the following relations

$$
\begin{gathered}
\Phi(\hat{\mathbf{x}}(\mathrm{k}))=\mathbf{x}(\mathrm{k})+\mathrm{T} \cdot \mathrm{f}(\hat{\mathbf{x}}(\mathrm{k})) \\
\mathrm{F}_{\mathrm{k}}=\mathrm{I}_{\mathrm{n} \times \mathrm{n}}+\left.\mathrm{T} \frac{\partial \mathrm{f}_{\mathrm{k}}\left(\mathrm{x}_{\mathrm{k}}\right)}{\partial \mathrm{x}_{\mathrm{k}}}\right|_{\mathrm{x}_{\mathrm{k}}=\hat{\mathrm{x}}_{\mathrm{k}}} \\
\mathrm{G}_{\mathrm{k}}=\mathrm{T} \cdot \mathrm{E}
\end{gathered}
$$

where $\mathrm{T}>0$ is the sample time. This system includes $\mathrm{n}=9$ states, the process noise covariance weight matrix $\mathbf{Q}_{\mathrm{k}}=\mathrm{E}\left(\mathbf{w}_{\mathrm{k}}^{\mathrm{T}} \mathbf{w}_{\mathrm{k}}\right) \in \mathfrak{R}^{\mathrm{n} \times \mathrm{n}}$ and the ship position and heading measurement noise covariance matrix $\mathbf{R}_{\mathrm{k}}=\mathrm{E}\left(\mathbf{v}_{\mathrm{k}}^{\mathrm{T}} \mathbf{v}_{\mathrm{k}}\right) \in \mathfrak{R}^{3 \times 3}$. These matrices usually exist in the diagonal form. For this system, the state vector was estimated using the algorithm of discrete-time extended Kalman filter (EKF) placed in table 5 .

\section{CASE OF STUDY}

Simulation and experimental tests were performed to assess the quality of the designed control system with different observers. The experimental tests were performed on the training ship "Blue Lady", the characteristics of which were given earlier. During the tests the ship position coordinates $(x, y)$ were measured by the DGPS system, while the ship heading $\psi$ was recorded by the gyro-compass. The velocities as surge $\mathrm{u}$, sway $\mathrm{v}$ and yaw $\mathrm{r}$ were estimated by the observer.

The complete control system, shown in Fig. 1, was modelled in the Matlab/Simulink environment, in which the simulation tests were performed. All blocks belonging to this scheme (navigation system, controller, propeller allocation, observer, ship) were recorded in the form of S-functions as M-files. The next step was the translation of all S-functions into the $\mathrm{C}$ language and their compilation to the form of MEX-files. During the simulation tests, following parameters of the PID-type multivariable controller were selected

$$
\begin{gathered}
K_{P}=\operatorname{diag}\left(\begin{array}{lll}
1 & 1 & 1
\end{array}\right) \\
K_{\text {I }}=\operatorname{diag}\left(\begin{array}{lll}
0.01 & 0.01 & 0.01
\end{array}\right) \\
K_{D}=\operatorname{diag}\left(\begin{array}{lll}
100 & 100 & 100
\end{array}\right)
\end{gathered}
$$

The designed extended Kalman filter was based on the following mathematical model of "Blue Lady"

$$
\begin{gathered}
M=\operatorname{diag}(23664.9 \\
D_{L}=\left[\begin{array}{ccc}
21.10 & 0 & 0 \\
0 & 259.8 & -855.4 \\
0 & -855.4 & 6130.5
\end{array}\right]
\end{gathered}
$$

The time constants for the bias were selected in the following way

$$
\mathrm{T}_{\mathrm{b}}=\operatorname{diag}(1000 \quad 1000 \quad 1000)
$$

The process noise covariance weight matrix

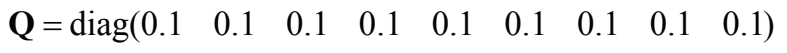

and the ship position and heading measurement noise covariance matrix

$$
\mathbf{R}=\operatorname{diag}(0.1 \quad 0.1 \quad 0.1)
$$

The simulation tests consisted in ship manoeuvring along different trajectories inside the harbour area in different weather conditions. The system was tested with different observers described earlier. Estimating the ship velocity components $\mathrm{u}, \mathrm{v}, \mathrm{r}$ from the position coordinates $(\mathrm{x}, \mathrm{y})$ measured by the DGPS and the ship course measured by the gyro-compass took into account the measurement noise.

After completing the simulation tests and confirming the correctness of system operation in various manoeuvring tasks performed with different observers, the next step was to initiate the designed control algorithm on a real ship. For this purpose the control and measurement system worked out in the Department of Ship Automation, Gdynia Maritime University was used [44]. The system makes use of Mathworks programmes and works in the xPC Target mode, which requires two computers. The software installed in the first computer, referred to as 'Host', includes Matlab with toolboxes: Simulink, Real Time Workshop and xPCTarget. The designed control algorithm comprising the navigation system, the controller, the propeller allocation and the observer is recorded in Simulink in the form of blocks with S-functions as C-MEX files, which were earlier tested in simulation tests. The second computer, bearing the name of 'Target' is equipped with an I/O card with analogue and numerical inputs and outputs and serial transmission ports (RS232/422/485) designed for communication with external devices. The communication between 'Host' and 'Target' is realised via Ethernet.

The Real Time Workshop generates the code ANSI/ ISO C from the block diagram stored in the Simulink and containing C-MEX files with the control system algorithm. The code generated in the above way is then compiled to the executable form and sent to 'Target'. After starting the scheme in Simulink stored in 'Host' the initiation of the real-time control takes place.

To assess the quality of operation of the designed control system, the test consisting in changing the ship position inside the harbour area was performed, as shown in Fig. 7. 


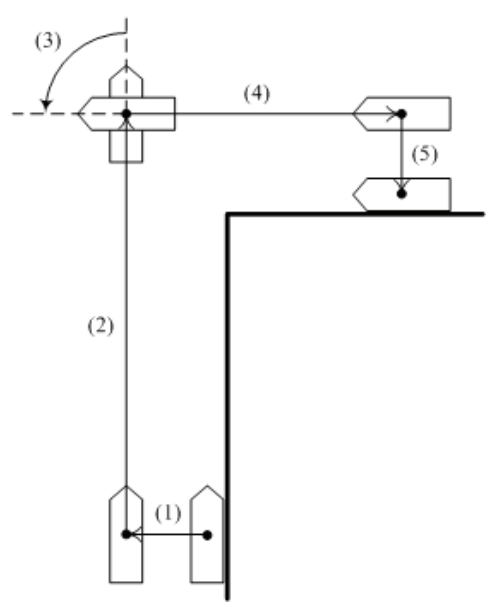

Fig. 7. Schematic overview of the performed manoeuvres

The test task included the following manoeuvres:

(1) lateral ship movement to port side by $7(\mathrm{~m})$,

(2) longitudinal ship movement forward by $38(\mathrm{~m})$,

(3) ship rotation by 90 degrees,

(4) longitudinal ship movement backward by 15 (m),

(5) lateral ship movement to port side by $3(\mathrm{~m})$.

The change of the performed manoeuvre was done when the ship was at a distance of $1 \mathrm{~m}$ from the turning point and the course difference was smaller than 5 degrees.

During the tests performed on the lake Silm the wind blew from the average direction $\psi_{\mathrm{w}}=300$ (deg) and at the average speed $\mathrm{V}_{\mathrm{w}}=3(\mathrm{~m} / \mathrm{s})$.

In Figure 8, the trajectory of the training ship "Blue Lady" is shown selected as reflected, successive positions of the hull, recorded by an electronic map of the water basin where the manoeuvers were performed.

Figures 9-11 present the results of the experimental tests performed using the control system shown in Fig. 1 with three observers (the discrete Kalman filter, the continuous Kalman-Bucy filter, and the extended discrete Kalman filter). The desired and measured vector position of the ship $\eta=[x$, $\mathrm{y}, \psi]^{\mathrm{T}}$ in $\mathrm{r}$-frame were shown in the left columns, whereas the desired and estimate ship velocity vector $v=[\mathrm{u}, \mathrm{v}, \mathrm{r}]$ ${ }^{\mathrm{T}}$ in surge, sway and yaw were shown in the right columns.

The quality of operation of the control systems with different observers was assessed by calculating the accuracy of ship position control. To assess the accuracy of the ship position control, three coefficients were calculated in form:

$$
\begin{aligned}
& x_{E}=\frac{1}{N} \sum_{k=1}^{N}\left|x_{d}^{r}(k)-x^{r}(k)\right| \\
& y_{E}=\frac{1}{N} \sum_{k=1}^{N}\left|y_{d}^{r}(k)-y^{r}(k)\right| \\
& \psi_{E}=\frac{1}{N} \sum_{k=1}^{N}\left|\psi_{d}^{r}(k)-\psi^{r}(k)\right|
\end{aligned}
$$

where $x_{d}^{r}, y_{d}^{r}, \psi_{d}^{r}$ are the set position coordinates, and the variables $\mathrm{x}^{\mathrm{r}}, \mathrm{y}^{\mathrm{r}}, \psi^{\mathrm{r}}$ represent the values measured by the

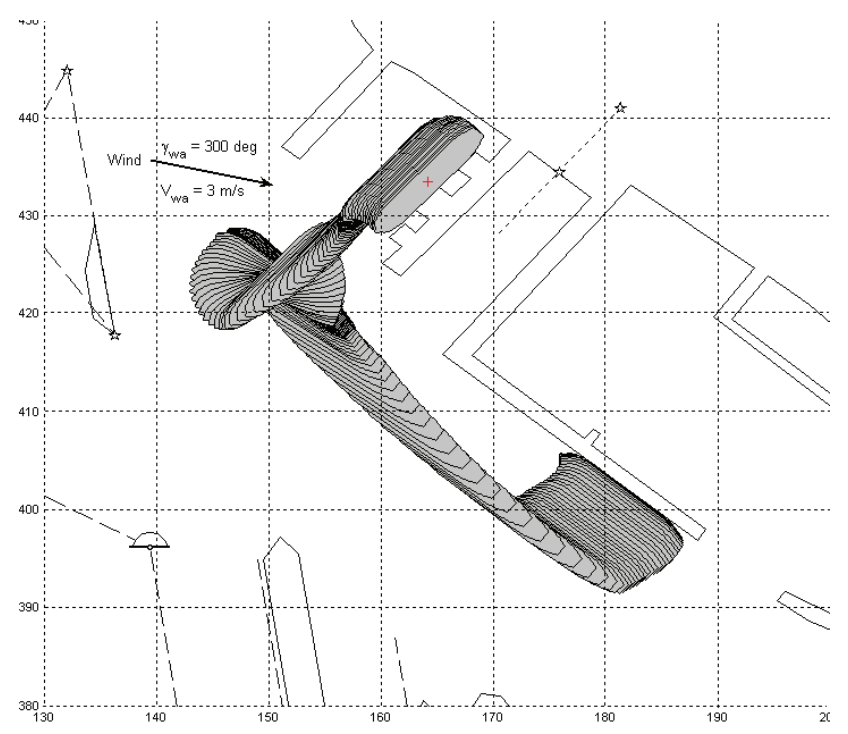

Fig.8. The analysed ship motion trajectory on the lake Silm, where $\gamma_{w a}$ is the average wind direction, $V_{w}$ is the average wind speed
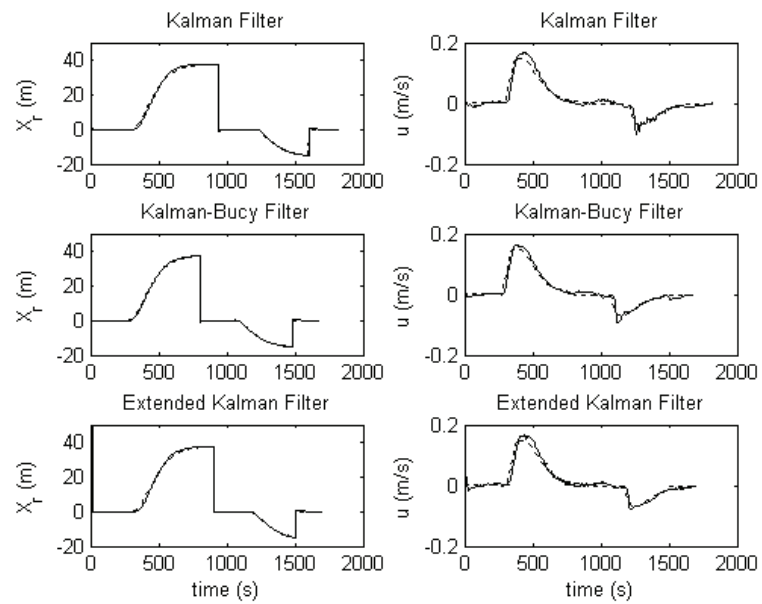

Fig. 9. Left column: coordinate $X$ of ship position in r-frame, desired values (dashed line), measured values (solid line). Right column: surge ship speed $u$ in b-frame, desired values (dashed line), estimated values (solid line) 

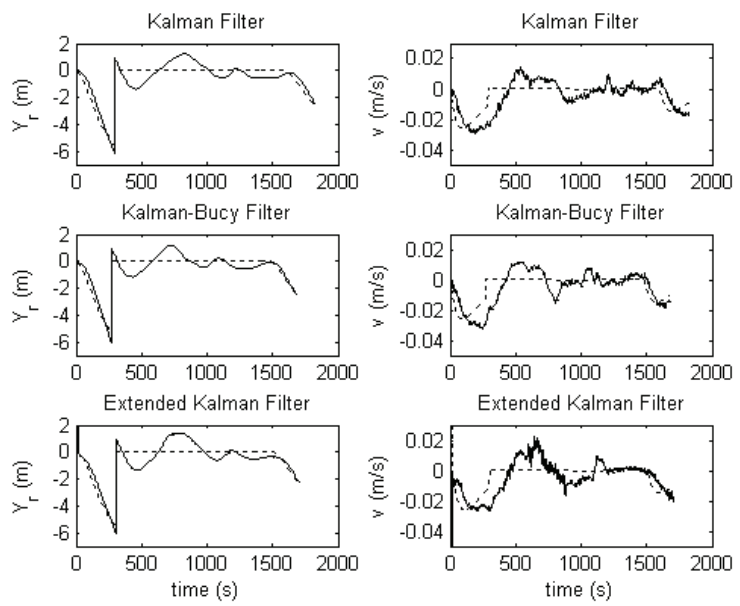

Fig. 10. Left column: coordinate Y of ship position in r-frame, desired values (dashed line), measured values (solid line). Right column: sway ship speed $v$ in b-frame, desired values (dashed line), estimated values (solid line)
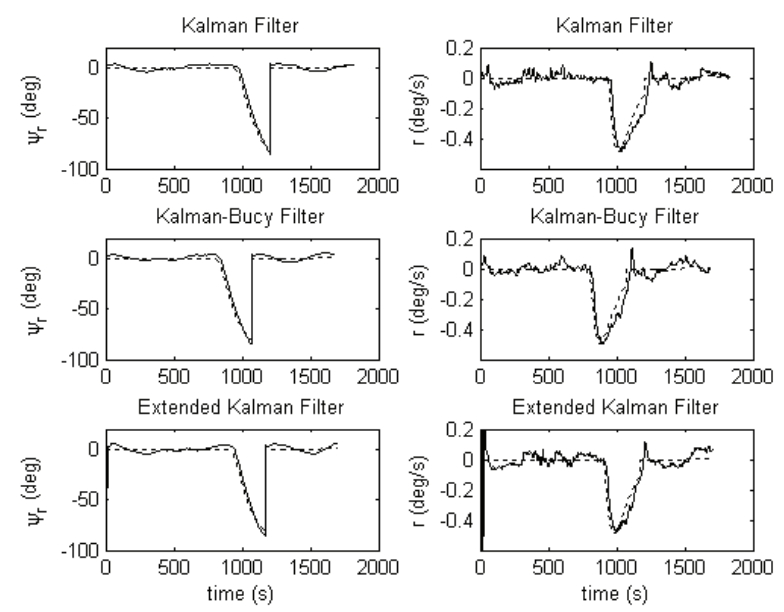

Fig. 11. Left column: ship heading $\psi$ in $r$-frame, desired values (dashed line), measured values (solid line). Right column: yaw ship speed $r$ in $b$-frame, desired values (dashed line), estimated values (solid line)

Tab. 6. Quality coefficients calculated based on the results obtained in experimental tests performed on the lake Silm

\begin{tabular}{|l|c|c|c|c|}
\hline & $\mathrm{x}_{\mathrm{E}}$ & $\mathrm{y}_{\mathrm{E}}$ & $\Psi_{\mathrm{E}}$ & $\mathrm{J}_{\mathrm{c}}$ \\
\hline Discrete Kalman Filter & 1.3523 & 0.4163 & 377.0888 & 5.5395 \\
\hline $\begin{array}{l}\text { Continous Kalman-Bucy } \\
\text { Filter }\end{array}$ & 0.2376 & 0.2984 & 402.5533 & 4.5615 \\
\hline Extended Kalman Filter & 1.3774 & 0.4738 & 387.4744 & 5.7259 \\
\hline
\end{tabular}

DGPS system and the gyro-compass in $\mathrm{r}$-frame with sampling time equal 1 (s). Based on the calculated mean values of the ship position deviations the functional having the following form was calculated

$$
\mathrm{J}_{\mathrm{c}}=\lambda_{1} \mathrm{x}_{\mathrm{E}}+\lambda_{2} \mathrm{y}_{\mathrm{E}}+\lambda_{3} \psi_{\mathrm{E}}
$$

where $\lambda_{1}=1.0, \lambda_{2}=1.0, \lambda_{3}=0.01$ are the weight coefficients. The results of obtained in the tests performed on the lake Silm are given in Table 6.

\section{REMARKS AND CONCLUSIONS}

In the article the quality of ship motion control was analysed for the case when the ship performs the position change manoeuvre inside the harbour area from one berth to another. The manoeuver was performed using three different observers for estimating the ship velocity components, i.e. surge $\mathrm{u}$, sway v and yaw $\mathrm{r}$, and was completed independently on the used observer.

Analysing the results collected in Table 6 leads to the conclusion that the best quality of control was obtained when the countinous-time Kalman-Bucy filter was used as the observer. The designed control system equipped with this observer reveals the highest accuracy of control.

\section{BIBLIOGRAPHY}

1. Strand J.P.: Nonlinear position control systems design for marine vessels, Ph.D. Thesis, Norwegian University Science and Technology, Deptment of Engineering Cybernetics, Trondheim, Norway, 1999.

2. Lindegaard K.-P.: Acceleration Feedback in Dynamic Positioning, Ph.D. Thesis, Norwegian University Science and Technology, Deptment of Engineering Cybernetics, Trondheim, Norway, 2003.

3. Fossen T.I., 1994. Guidance and control of ocean vehicles, John Wiley and Sons, Chichester, UK, 1994.

4. Amerongen J.V.: Adaptive Steering of Ships - Model Reference Approach, Automatica, Vol. 20, No 1, 1984, pp. 3-14.

5. Saelid S., Svanes T., Onshus T., Jensen N.A.: Design considerations, analysis and practical experince with an adaptive ship's autopilot, In: Proceedings of the $9^{\text {th }}$ IFAC World Congress, Budapest, Hungary, 1984, pp. 35-40.

6. Holzhuter T., Strauch H.: A Commercial Adaptive Autopilot for Ships: Design and Operational Experiences, In: Procedings of the $10^{\text {th }}$ IFAC World Congress, Munch, Germany, 1987, pp. 226-230.

7. Amerongen J.V., Nauta Lemke H.R.V.: Recent development in automatic steering of ships, Journal of Navigation, Vol. 39, No 3, 1986, pp. 349-362.

8. Amerongen J.V., Land E.F.A.: An adaptive autopilot for track-keeping, Ship Operation Automation, III, Editor J. Vlietstra, North-Holland Publishing Company, 1980, pp. 105-114.

9. Chocianowicz W., Pejaś J.: Adaptive control system for steering the ship along the desired trajectory - based on the optimal control and filtering theory, In: Proceedings of the Control Applications in Marine Systems (CAMS-92), 
Genova, Italy, 1992, pp. 319-335.

10. Lu X.R., Jiang J.H., Huang Y.X.: Design of a selftuning adaptive track-keeping control system for ships, In: Proceedings of the International Conference on Modelling and Control of Marine Craft, University of Exeter, U.K., 1990, pp. 178-192.

11. Holzhüter T.: LQG approach for the high-precision track control of ships, IEE Proceedings: Control Theory Application, Vol. 144, No 2, 1997, pp. 121-127.

12. Bertin D.: Track-keeping controller for a precision manoeuvring autopilot, In: Proceedings of the IFAC Conference Control Application in Marine Systems (CAMS-98), Fukuoka, Japan, 1998, pp. 155-160.

13. Messer A.C., Grimble M.J.: Robust Track-keeping Control, Procedings of IFAC Workshop on Control Applications in Marine Systems (CAMS-92), Genova, Italy, 1992, pp. 371-380.

14. Vukic Z., Omerdic E., Kuljaca L.: Improved fuzzy autopilot for track-keeping, In: Proceedings of IFAC Conference on Control Application in Marine Systems (CAMS-98), Fukuoka, Japan, 1998, pp. 135-140.

15. Velagic J., Vukic Z., Omerdic E.: Adaptive fuzzy ship autopilot for track-keeping, Control Engineering Practice, Vol. 11, No 4, 2003, pp. 433-443.

16. Zhang Y., Hearn G.E., Sen P.: A Neural Network Approach to Ship Track-Keeping Control, IEEE Journal of Ocean Engineering, Vol. 21, No 4, 1996, pp. 513-527.

17. Galbas J.: Synthesis of precise ship steering system making use of thrusters, Ph.D. Thesis, Technical University of Gdańsk, Poland, 1988. (in Polish)

18. Hasegawa K., Kitera K.: Mathematical Model of Manoeuvrability at Low Advance Speed and its Application to Berthing Control, In: Proceedings of the $2^{\text {nd }}$ Japan-Korea Joint Workshop of Ship and Marine Hydrodynamics, Osaka, Japan, 1993, pp. 144-153.

19. Gierusz W.: Simulation model of the shiphandling training boat "Blue Lady", In: Proceedings of the $5^{\text {th }}$ IFAC Conference on Control Application in Marine Systems (CAMS-01), 2001, Glasgow, Scotland.

20. Skjetne R., Smogeli O., Fossen T.I.: A nonlinear ship maneuvering model: Identification and adaptive control with experiments for a model ship, Modeling, Identification and Control, Vol. 25, No 1, 2004, pp. 3-27.

21. Obreja D., Nabergoj R., Crudu L., Pacuraru-Popoiu S.: Identification of hydrodynamic coefficients for manoeuvring simulation model of a fishing vessel, Ocean Engineering, Vol. 37, No 7-8, 2010, pp. 678-687.

22. Herrero R.R., Gonzales F.J.V.: Two-step identification of non-linear manoeuvering models of marine vessels, Ocean Engineering, Vol. 53, No 10, 2012, p. 72-82.

23. Shouji K., Ohtsu K., Mizoguchi S.: An Automatic Berthing Study by Optimal Control Techniques, In: Proceedings of the IFAC Workshop on Control Application in Marine Systems (CAMS-92), Genova, Italy, 1992, pp. 185-194.

24. Ohtsu K., Shouji K.: Minimum-time maneuvering of ships with wind disturbances, Control Engineering Practice, Vol. 4, No 3, 1996, pp. 385-392.

25. Okazaki T., Ohtsu K. Shouji K.: A study of minimum time berthing solution, In: Proceedings of the $5^{\text {th }}$ IFAC Conference on Manoeuvring and Control of Marine Craft (MCMC-2000), Aalborg, Denmark, 2000, pp. 135-139.

26. Mizuno N., Kuroda M., Okazaki T., Ohtsu K.: Minimum time ship manoeuvring method using neural network and nonlinear model predictive compensator, Control Engineering Practice, Vol. 15, No 6, 2007, pp. 757-765.

27. Sarioz K., Narli E.: Assesssment of manoeuvering performance of large tankers in restricted waterways: a real-time simulation approach, Ocean Engineering, Vol. 30, No 12, 2003, pp. 1535-1551.

28. Zhang Y., Hearn G.E. Sen P.: A Multivariable Neural Controller for Automatic Ship Berthing, Journal of IEEE Control System, Vol. 17, No 8, 1997, pp. 31-44.

29. Im N., Keon L.S., Do B.H.: An application of ANN to automatic ship berthing using selective controller, TransNav - International Journal of Marine Navigation and Safety of Sea Transportation, Vol. 1, No 1, 2007, pp. 101-105.

30. Skjetne R., Fossen T.I., Kokotovic P.V.: Adaptive maneuvering, with experiments, for a model ship in a marine control laboratory, Automatica, Vol. 41, No 2, 2005, pp. 289-298.

31. Gierusz W., Nguyen Cong V., Rak A., Maneuvering control and trajectory tracking of very large crude carrier, Ocean Engineering, Vol. 34, No 7, 2007, pp. 932-945.

32. Morawski L., Nguyen Cong V.: Ship Control in Manoeuvering Situation with Fuzzy Logic Controllers, TransNav - International Journal of Marine Navigation and Safety of Sea Transportation, Vol. 2, No 1, 2008, pp. 77-84.

33. Morawski L., Nguyen Cong V.: Problem of Stopping Vesssel at the Waypoint for Full-Mission Control Autopilot, TransNav - International Journal of Marine Navigation and Safety of Sea Transportation, Vol. 4, No 2, 2010, pp. 151-156.

34. Lee G., Surendran S., Kim S.-H.: Algorithms to control the moving ship during harbour entry, Applied Mathematical Modelling, Vol. 33, No 5, 2009, pp. 2474-2490.

35. Bui V.P., Kawai H., Kim Y.B., Le K.S.: A ship berthing system design with four tug boats, Journal of Mechanical Science and Technology, Vol. 25, No 5, 2011, pp. 1257-1264.

36. Tomera M.: Discrete Kalman filter design for multivariable ship motion control: experimental results with training ship, Joint Proceedings of Gdynia Maritime Academy and Hochschule Bremerhaven, Bremerhaven, 2010, pp. 26-34.

37. Tomera M.: Kalman-Bucy filter design for multivariable ship motion control, TransNav - International Journal of Marine Navigation and Safety of Sea Transportation, Vol. 5, No 3, 2011, pp. 345-355.

38. Tomera M.: Nonlinear observers design for multivariable ship motion control, Polish Maritime Research, Issue Special, Vol. 19, No 74, 2012, pp. 50-56.

39. Tomera M.: Dynamic positioning system for „Blue Lady”. Simulation tests, Polish Maritime Research, Issue 
Special, Vol. 19, No 74, 2012, pp. 57-65.

40. Foundation for Safety of Navigation and Environment Research, 2012. <www.ilawashiphandling. com.pl>

41. Fossen T.I.: Marine Control Systems: Guidance, Navigation, and Control of Ships, Rigs and Underwater Vehicles, Marine Cybernetics, Trondheim, Norway, 2002.

42. Brown R.G., Hwang P.Y.C.: Introduction to Random Signals and Applied Kalman Filtering with Matlab Exercises and Solutions, Third Edition, John Wiley \& Sons, Inc, 1997.

43. Fossen T.I.: Handbook of Marine Craft Hydrodynamics and Motion Control, John Wiley \& Sons, 2011.

44. Pomirski J., Rak, A., Gierusz W.: Control system for trials on material ship model, Polish Maritime Research, Special Isssue, Vol. 19, No 74, 2012, pp. 25-30.

\section{CONTACT WITH THE AUTHOR}

Mirosław Tomera, Ph. D.

Gdynia Maritime University,

Faculty of Marine Electrical Engineering,

Department of Ship Automation,

Morska 81/87 Str.

81-225 Gdynia, POLAND

e-mail: tomera@am.gdynia.pl 